Open Access

\title{
CFD investigation of flow through a centrifugal compressor diffuser with splitter blades
}

\author{
M. G. Khalafallah, H. S. Saleh, S. M. Ali and H. M. Abdelkhalek * (D)
}

\author{
*Correspondence: hesham61975@ \\ gmail.com \\ Mechanical Power Department, \\ Faculty of Engineering, Cairo \\ University, Giza, Egypt
}

\begin{abstract}
The aerodynamic losses in centrifugal compressors are mainly associated with the separated flow on the suction sides of impeller and diffuser vanes. The overall performance of such compressors can be improved by adding splitter vanes. The present work examines the effect of varying the geometrical location of the splitter vanes in the diffuser on the overall performance of a high-speed centrifugal compressor stage of a small gas turbine. To increase the pressure recovery through the diffuser, two radial sets of vanes are used. The first set of vanes (diffuser-1) is equipped with splitter vanes, placed mid-distance between the main vanes, while the vanes of the second set (diffuser-2) are conventional vanes. Flow through the compressor was simulated using the ANSYS 19 workbench program. Flow characteristics and compressor performance were obtained and analyzed for different circumferential positions of the splitting vanes relative to the main vanes of diffuser-1. The study covered seven positions of the splitter vanes including the original design of the diffuser where the splitter vanes were located at mid-distance between the main vanes. The analysis shows that, at design conditions, selecting the position of the splitter vanes to be nearer to the pressure side of the main vanes improves the stage performance. In the present study, locating the splitters at 33\% of the angular distance between the main vanes leads to the best performance, and a significant improvement in the overall stage performance is recorded. The pressure recovery coefficient is raised by about $17 \%$, the pressure ratio is increased by about $1.13 \%$, and the stage efficiency is increased by about $2.01 \%$, compared to the original splitter position. Performance improvement is related to the suppression of the flow separation and the more uniformity of flow. On the contrary, further moving the splitter closer to the main blade, the pressure recovery coefficient is decreased by about $2 \%$ than the position of $33 \%$ of the angular distance, but still higher than the original position by about 15\% and a limited improvement in the compressor performance is noticed. Moving the splitter far out the main blade annihilates the static pressure recovery of the diffuser by about 2:7\% compared with the original position. So, for the investigated compressor, the best position of the splitter blade in the circumferential direction, which provides the best stage performance in our parametric analysis, is not necessary to be at the mid-angular distance between the diffuser's main blades, but it is achieved by moving the splitter
\end{abstract}

(c) The Author(s). 2021 Open Access This article is licensed under a Creative Commons Attribution 4.0 International License, which permits use, sharing, adaptation, distribution and reproduction in any medium or format, as long as you give appropriate credit to the original author(s) and the source, provide a link to the Creative Commons licence, and indicate if changes were made. The images or other third party material in this article are included in the article's Creative Commons licence, unless indicated otherwise in a credit line to the material. If material is not included in the article's Creative Commons licence and your intended use is not permitted by statutory regulation or exceeds the permitted use, you will need to obtain permission directly from the copyright holder. To view a copy of this licence, visit http://creativecommons.org/licenses/by/4.0/. The Creative Commons Public Domain Dedication waiver (http://creativecommons.org/publicdomain/zero/1.0/) applies to the data made available in this article, unless otherwise stated in a credit line to the data. 
to about $33 \%$ of the angular distance where the diminished loss from the suppressed flow separation is more prevailing and the instigated friction losses from splitter surfaces are less critical.

Keywords: Centrifugal compressor, Vaned diffuser, Splitter Blades, Numerical simulation, Flow separation

\section{Introduction}

Centrifugal compressors are used in a variety of applications in contemporary industry, including aerospace, oil, chemicals, metallurgy, gas field, automobile engines, air separation, and others. The fluid initially enters the impeller in a centrifugal compressor, where the energy is transferred to the gas. The impeller will create a complicated flow field, with significant variations in velocity and flow angles in both the circumferential and axial directions [1-3].

At the impeller output, a jet-wake structure is often observed, which is quite similar to the mixing of parallel flows. It generally denotes the impeller outlet's non-uniform discharge flow caused by tip leakage flow, high curvature, boundary layer formation, centrifugal force, and Coriolis force. So, the flow entering the diffuser is unsteady and distorted, with a large quantity of kinetic energy to be converted to static pressure increase, especially for high-speed compressors. The flow field in the diffuser is further affected by the pressure non-uniformity generated by the volute in the off-design state [4]. As a result, the diffuser is sandwiched between two extremely complex flow components, both of which have an impact on its flow field and performance. The diffuser's design might have a negative impact on the compressor's overall efficiency. So, it is critical for the designer to understand the impact of various factors on the flow through the compressor in order to design an efficient compressor.

Nearly $30: 40 \%$ of the total input work to the centrifugal compressor is transferred to the kinetic energy of the flow at the impeller's exit. To attain a high level of efficiency, as much kinetic energy as feasible must be converted into a static pressure increase. Two different methods can be used to convert the kinetic energy to pressure increase in the diffuser:

1. By increasing the flow area, the velocity is reduced and the static pressure is increased.

2. Changing the mean flow path radius with guide vanes, which reduces the radial and tangential velocity of the flow while increasing the static pressure.

As shown in Fig. 1, the diffuser can be vaneless or vaned. Because of the extended logarithmic spiral flow path, which produces large friction losses, the former allows for a broader working range but has poorer efficiency and pressure recovery. Because the required quantity of diffusion is dependent on the diffuser outlet radius, this flow path cannot be easily decreased. Inserting diffuser vanes is the most frequent method for shortening the flow path. The mean flow path radius is changed by these vanes, which reduces both the radial and tangential velocities of the flow, causing an increase in the static pressure. The compressor stage efficiency and pressure rise would be improved, 


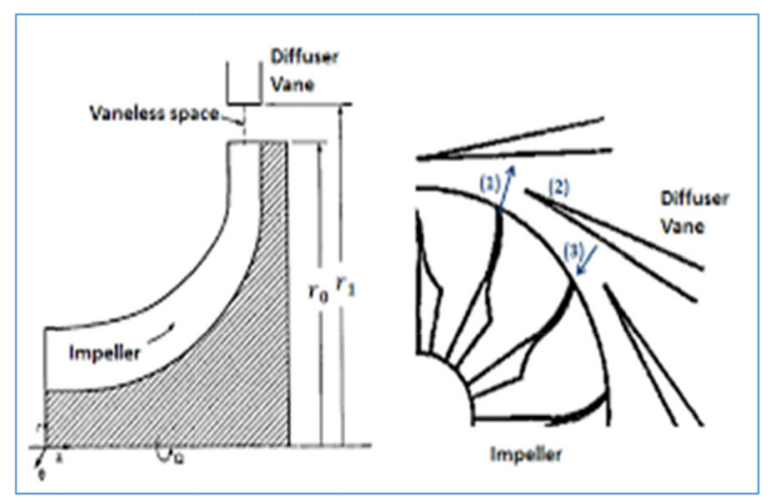

Fig. 1 Vaneless and vanned diffuser

but the working range would be reduced. Splitter vanes are typically employed to improve flow guiding and decrease the effects of flow separation in radial vaned diffusers.

The main objective of the present work is to study the effect of the relative location of splitter vanes, with respect to diffuser main vanes, on the flow characteristics through the diffuser and on the performance of the compressor stage.

The pressure loading on the blades, which is the pressure differential between suction and pressure sides of the impeller blade, and the inlet Mach number values are two of the most important limiting variables in centrifugal compressor design.

This pressure loading, and therefore the pressure gradient on the suction side at the vane exit, must be considered in the compressor's design since it impacts the compressor's performance. If this pressure gradient exceeds a specific value on the suction side near the vane exit, the fluid flow separates from the suction side at that point, resulting in extreme energy loss. From the impeller's leading edge to its trailing edge, the blade pressure loading rises. As a result, near the impeller's exit, flow separation becomes more likely [5].

Increasing the number of blades is an imperative solution to improve flow guidance and reduce blade loading, but this increase leads to more friction loss and a larger blockage coefficient. So, there is the insistent needing for using splitter blades, which are shorter blades inserted between full-length blades, to reduce the friction and blockage effects, consequently reducing the separation process in impeller and diffuser and avoiding choking of the flow in the throat of radial impellers and diffusers and achieving high-pressure ratio [6].

Several studies have been conducted to examine the appropriateness of utilizing splitter vanes in the impeller blade passage to address its advantages. For saving time and effort, using a design analysis tool like CFD is the cornerstone to perform the numerical study. Analyzing the complicated flow in a centrifugal compressor has been a good proof for the importance of using such a technique [7].

By using splitters in the impeller's design, it is monitored that its primary effect is to reduce both the load on the main blades and the jet/wake effect at the rotor exit. Fradin [8] conducted a series of experiments on the flow fields of two centrifugal rotors, one with splitters and the other without. The flow field was transonic in both situations, and the study found that when splitters were employed, the flow field at the rotor (impeller) outlet was more uniform and homogenous. 
Gui et al. [9] tested two centrifugal fans in the incompressible flow regime: one with no splitter and the other using varied geometry splitters. They looked carefully at how splitter length, stagger angle, and circumferential location affected the fans' performance. The results remarked that by using splitters, the load and velocity gradients on the main blades are reduced, but they also contribute extra losses that are highly dependent on their profile shape. When the splitter is situated closer to the suction side of the main blade, the pressure recovery coefficient rises. Also, by lengthening the splitter, the pressure recovery coefficient can be increased with no influence on the efficiency.

Many studies have also been carried out to look at the impact of impeller-diffuser interaction. These studies discovered that there is an optimum radial distance between the impeller blades' trailing edge and the diffuser blades' leading edge, which is one of the key factors for achieving peak performance $[10,11]$.

On the contrary, limited researches have been done on the diffusers to address the suitability of using splitter vanes in the blade passage of radial diffusers. The design of vaned diffusers (VDs) is generally based on engineering knowledge and experimental data.

However, because a solid design method has not yet been created, these characteristics pose a constraint when a VD must be used, for example, in centrifugal compressors of small-scale turbochargers. In recent years, the coupling of computational fluid dynamics (CFD) codes with optimization approaches has gained popularity in turbomachinery and has proven to be effective in overcoming the difficulty of constructing a VD based on empirical correlations. Nevertheless, there are few researches on this issue in the literature and even fewer works on optimizing vanned diffusers for turbocharger centrifugal compressor performance.

Teipel et al. [12] examined the flow field in radial diffusers for a high-pressure ratio centrifugal compressor utilized in small gas turbine units theoretically. The tested compressor is equipped with a (19 blades) radial diffuser. In addition, infinitely thin splitter vanes were placed along the center line of each diffuser channel to divide each channel into two equal sub-passages. The splitter's leading edge is mounted near the throat of the main diffuser channel. The calculations for inviscid transonic flow fields were done using a time marching technique, and the purpose of this study is to illustrate how the splitter vanes affect both the key features of the flow pattern and the diffuser's overall performance.

The fraction of mass flow in the two splitter channels is the concern of Oana et al. in their study [13]. Splitters were usually placed in the mid-angular distance between the main blades, but they modified the splitter incidence angle at its circumferential location to maintain an equal mass flow rate between the two channels. At a certain pressure ratio, this led to improving the impeller's overall efficiency.

Abdul Nassar et al. [14] modeled a centrifugal compressor with 18 backswept main blades to be used in a turbocharger. Firstly, they studied the effect of different tip clearances on the compressor performance at different speeds. It was monitored that by increasing the tip clearance, the compressor performance would deteriorate in the form of decreasing the efficiency and the pressure ratio of the compressor and turning the flow to a jet-wake pattern at the impeller's exit. Then, they replaced 9 full blades with 9 splitters and varying their circumferential position at a different spacing from the suction side of the main blade and varying their length ratio and studied the effect of these variations on the overall compressor performance. They concluded that the optimum splitter length ratio is 0.5 , and repositioning the splitter at different circumferential 
positions did not have any effect on the flow structure and the overall compressor performance.

Malik et al. [15] used a centrifugal compressor type (DDA 404-III) with a vaneless diffuser; the original impeller was designed by 15 backswept full blades and 15 splitters. The impeller was modified by adding multi splitters as follows: adding a big splitter close to the pressure surface and small splitter close to the suction surface. The modified impeller would be a total of 33 blades (11 main blades, 11 big splitters, and 11 small splitters). The flow conditions and impeller definition such as backswept, thickness, and theta angle are kept the same as the original impeller, to show only the effect of adding multi-splitters on the overall compressor performance. It was remarked that the compressor performance was improved in the form of increasing the efficiency by about $2 \%$, increasing the pressure ratio by $10 \%$ and decreasing the relative Mach number at the impeller's inlet.

Madhwesh et al. [16] performed a numerical analysis for the effect of adding splitters and varying their geometric location on the overall performance of the centrifugal fan stage. The used impeller is composed of 12 backward swept blades and was supplied by splitters, which had the same aerofoil shape as the main blades. The splitters were provided on the leading edge of the impeller and on the trailing edge of the impeller, at different circumferential positions between the impeller's main blades. Six configurations were formed by these variations and compared with the original design. It was recorded that the overall performance of the centrifugal fan was improved by providing the splitters on the leading edge, especially at the mid-pitch between the main blades, in the form of increasing the static pressure recovery coefficient, while locating the splitters on the trailing edge had an adverse effect on the fan performance due to the formation of large recirculation zone as well as a flow instability.

Xiao et al. [17] numerically investigated the improvement of a high-pressure ratio centrifugal compressor performance by applying splitters to a 19-blade vaned diffuser. The applied splitters were located at the mid-pitch between the diffuser's main blades and had the same specifications as the main blade except its length, as shown in Fig. 2. When the splitter was applied in the vaned region, by increasing its length ratio from 0.10 to 0.70 of the main blade, it was observed that the flow separation has been successfully suppressed and there was a significant improvement in the diffuser pressure recovery coefficient and the whole stage efficiency. Locating the splitter at the semivaneless region, by further increasing its length ratio from 0.8 to 0.95 , the compressor performance was deteriorated due to the resulting higher shock strength and thus the shock loss. Hence, the diffuser pressure recovery was decreased by 0.03 , and the whole stage efficiency was dropped by $0.7 \%$.

Yagnesh Sharma et al. [7] used a centrifugal fan supplied by a vaned diffuser to perform an extensive numerical analysis for the effect of positioning splitter vanes in discrete circumferential locations on the trailing and leading edges of the impeller and the diffuser. The used impeller was equipped with 13 2-D backswept blades, and the used diffuser consisted of 13 blades. Supplemented splitters were selected to be the same aerofoil shape of the main blade in the impeller or the diffuser but with a length ratio of 0.25 of the main blade.

The analysis proved that the overall stage performance was improved to a larger extent by applying the splitters on the trailing edge of the diffuser, due to streamlining 


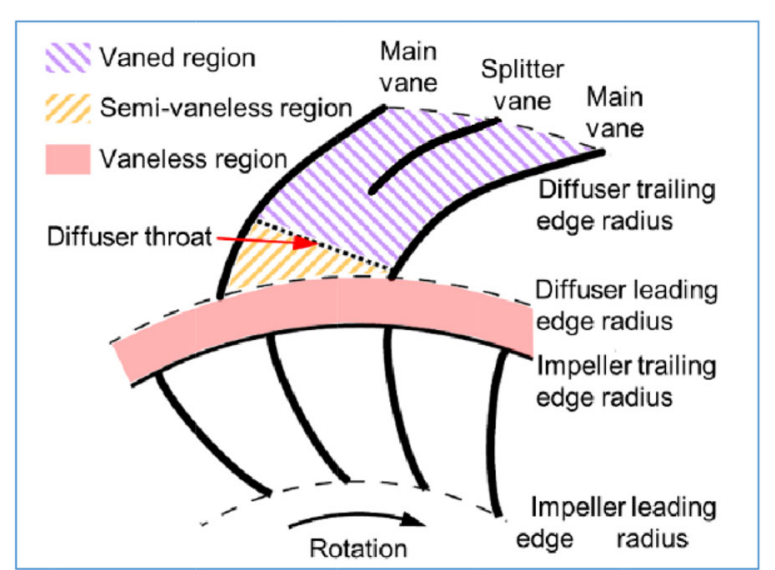

Fig. 2 Schematic of the diffuser design

the flow in the whole flow passage and vanishing the formation of a rotating stall. There is a peripheral improvement in the performance by applying the splitters, in the mid-pitch between the main blades, on the trailing edge of the impeller, and the leading edge of the diffuser, while the stage performance was deteriorated by locating the splitter on the trailing edge, near the suction side of the impeller's main blade, due to the formation of recirculation zone plus the flow instability.

It can be noted from the above literature survey that a CFD analysis for the effect of splitter blades in diffusers on the performance of high-pressure ratio centrifugal compressors, as well as its effect on impeller-diffuser interaction, has not been adequately investigated in the long run.

Hence, to fill this gap, the current study is devoted to numerically examine the several splitter design choices in a vaned diffuser of a high-pressure ratio centrifugal compressor. The basic configuration of the splitters is extracted from the main vane. To ensure appropriate stage matching, the choke mass flow rate of the diffuser is maintained constant. Diffusers with different splitter angular locations have been investigated to analyze their effect on the fluid flow in the radial diffuser passage and on the overall performance of the centrifugal compressor.

\section{Methods}

1. The objectives of this study are as follows:

(a) To achieve further understanding of the effect of varying the geometrical location of the splitter vanes on the overall performance of a high-speed centrifugal compressor stage of a small gas turbine

(b) To optimize the circumferential position of the splitter in the vaned diffuser

(c) To improve the overall centrifugal compressor performance, in the form of increasing the pressure ratio and the efficiency of the compressor 
2. This study is organized as follows:

(a) Section 1 introduces the basic compressor theory, including the flow passage through its components, commonly observed flow phenomena, sources of loss generation, and types of diffusers; after that, a literature survey reviewed the existing experimental and numerical works on the centrifugal compressor to address the benefits of using the splitter vanes in the blade passage of impeller.

(b) Section 2 presents a brief about the objectives, design, and setting of this study.

(c) Section 3 presents the main dimensions and grid generation of the centrifugal compressor components by "ANSYS Turbo-Grid" program.

(d) Sections 4 presents a brief introduction to the turbomachinery modeling techniques by the "ANSYS CFX Pre 19" program which solves the 3D steady compressible Reynolds-averaged Navier-Stokes (RANS) equations and using a finite-volume method to discretize the equations, followed by the numerical conditions.

(e) Section 5 examines the accuracy of the numerical model by comparing the numerical results with experimental data at different speeds and mass flow rates.

(f) Section 6 presents the results from the simulation that are discussed in detail due to the effect of varying the geometrical location of the splitter vanes on the overall performance of a high-speed centrifugal compressor stage.

(g) Section 7 summarizes the conclusions of the study.

\section{Computational domain setup}

The present work was carried out on a centrifugal compressor stage designed for a pressure ratio of 1.9 and a mass flow rate $5.4 \mathrm{~kg} / \mathrm{s}$. This is the last stage, after the ninestage axial flow compressor, of a high-pressure ratio compressor. The radial bladed impeller is followed by two separate radial diffusers where the first diffuser is provided with splitter blades and the second diffuser guides the flow to exit radially. The main dimensions and grid structure of the stage's components are shown in Table 1.

Because of periodicity structural characteristics of the geometry of compressor's components, only a single channel holding the inlet duct, a full blade of the impeller, 2 vanes (main + splitter) of the vaned (diffuser-1), and a full blade of diffuser-2 are modeled. A powerful tool "ANSYS Turbo-Grid" is used to automate the generation of highquality hexahedral meshes for the blade passages in the rotating impeller and the diffusers [18], while preserving the underlying geometry, as seen in Fig. 3.

The grid convergence study was done for the final model. Initially, coarse grid of (481130) elements is used to plot the characteristic curves at design speed. Subsequently, the grid is increased to (1021734) elements and (2015034) elements.

Grid resolution is the main factor for the result accuracy. Grid refinement can be continued until the grid independence limit (GIL) is reached, at which point the acquired results do not have considerable change. The total pressure at the compressor outlet at design speed is taken to evaluate the grid independence test of the computational domain. Various levels of grid refinement used for the grid independence test are shown in Table 2. 
Table 1 Main dimensions and grid structure of centrifugal compressor components

\begin{tabular}{|c|c|}
\hline \multicolumn{2}{|l|}{ Impeller } \\
\hline Impeller inlet diameter, $\mathrm{mm}$ & $\begin{array}{l}92 \text { (hub) } \\
139 \text { (shroud) }\end{array}$ \\
\hline Impeller exit diameter, mm & 182 \\
\hline Impeller exit blade height, mm & 10 \\
\hline Impeller leading edge axial lean angle, degree & -29 \\
\hline Impeller trailing edge axial lean angle, degree & -2 \\
\hline Impeller speed, rpm & 43,500 \\
\hline Number of blades & 36 ( radial) \\
\hline Blade spanwise-backswept from radial, degree & $32-42$ \\
\hline Nodes & 372,260 \\
\hline Elements & 348,398 \\
\hline \multicolumn{2}{|l|}{ Diffuser-1 } \\
\hline Inlet diameter of diffuser-1, mm & 190 \\
\hline Exit diameter of diffuser-1, mm & 250 \\
\hline Main vane: height - length, mm & $10-46$ \\
\hline Main vane thickness, mm & 1 \\
\hline Main vane angle, degree & $65^{\circ}$ \\
\hline Splitter vanes: height - length, mm & $10-32$ \\
\hline Splitter vane thickness, mm & 1 \\
\hline Splitter vanes angle, degree & $59^{\circ}$ \\
\hline Number of vane/splitter pairs & 30 (straight) \\
\hline Nodes & 372,890 \\
\hline Elements & 349,792 \\
\hline \multicolumn{2}{|l|}{ Diffuser-2 } \\
\hline Inlet diameter of diffuser-2, mm & 251 \\
\hline Exit diameter of diffuser-2, mm & 410 \\
\hline Number of vanes & 30 (curved) \\
\hline Leading edge: height - thickness, mm & $11.4-5.2$ \\
\hline Trailing edge: height - thickness, mm & $20-6.1$ \\
\hline Chord of vanes, mm & 80 \\
\hline Nodes & 344,260 \\
\hline Elements & 323,544 \\
\hline
\end{tabular}

The total pressure at the compressor outlet with respect to the grid refinement level is shown in Fig. 4. The results illustrate that there are deviations in the computed value of the total pressure at the compressor outlet for the grid refinement level from coarse to fine. The variation in the results for the grids from (1021734) to ( 2015034) is less than $2 \%$, so all further analysis is carried out by a medium grid to save time and effort.

\section{Boundary conditions}

By the end of the meshing stage, it is exported to the physics definition stage. Specifying boundary conditions as inlet, outlet, walls, flow, and thermal variables, on the CFD 


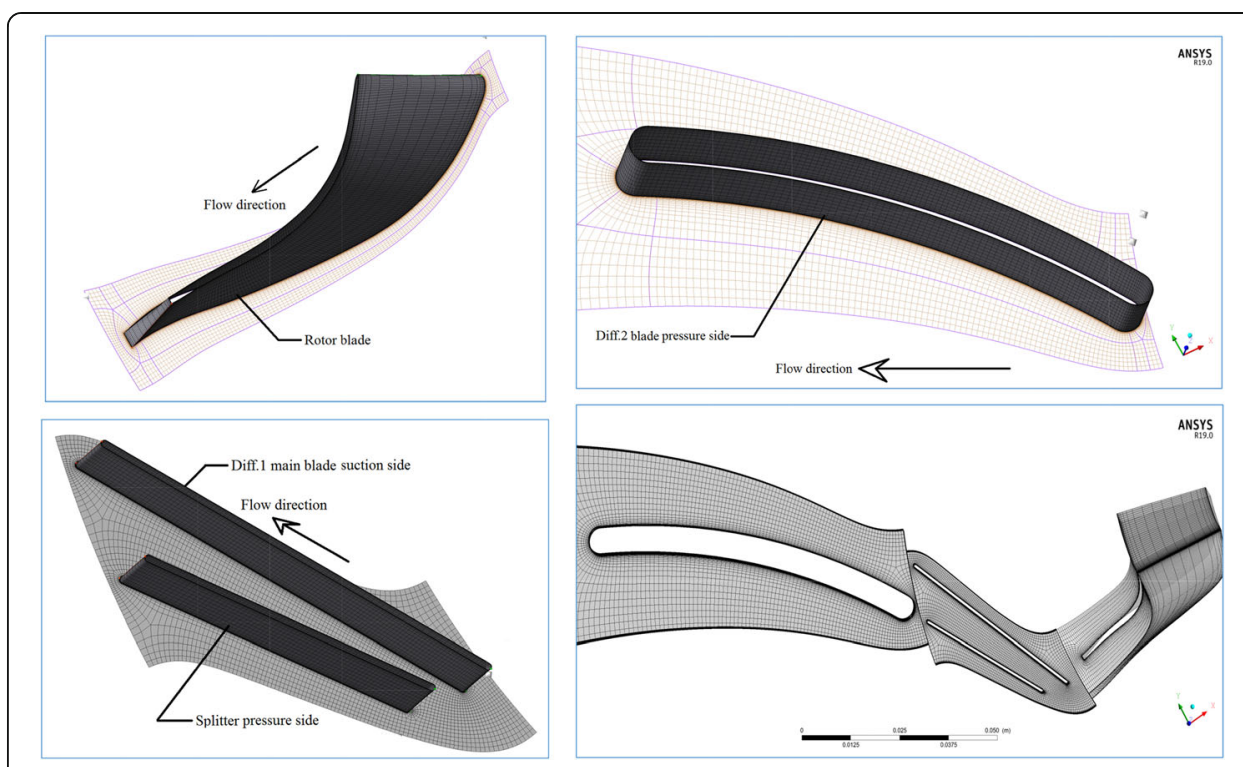

Fig. 3 Grid structure of the computational domain for the rotor and diffusers

model's borders, is the baseline for this stage. The type of fluid material and its axis of rotation, if the fluid zone is rotating, must be specified carefully as input boundary conditions to define the fluid zone.

Moving domains, or parts of these domains, problems can be handled in CFX by applying the rotating fluid zone. The rotating frame option was utilized to simulate the flow in the compressor. Due to sweeping the domain periodically by the compressor rotor blades, the flow is unsteady in an inertial frame in this case. However, in the absence of stators, computations may be performed in a domain that moves with the rotating part. In this case, the flow is considered steady relative to the rotating frame.

The experimental total pressure and total temperature at the inlet boundary are specified, and a $5.4 \mathrm{~kg} / \mathrm{s}$ mass flow rate is given at the outlet boundary of the computational domain. No-slip condition and zero heat transfer are set for the walls, and the turbulence is simulated using a SST model with a turbulent length scale, which describes the size of the large energy-containing eddies in the turbulent flow of $0.25 \mathrm{~m}$ and turbulence intensity of $5 \%$.

By using a finite volume technique, "Ansys -CFX Pre 19" solves the 3D steady compressible Reynolds-averaged Navier-Stokes (RANS) equations by dividing each region

Table 2 Various levels of grid refinement for centrifugal compressor components

\begin{tabular}{|c|c|c|c|c|c|c|}
\hline \multirow[t]{2}{*}{ Domain } & \multicolumn{3}{|l|}{ Nodes } & \multicolumn{3}{|c|}{ Elements } \\
\hline & Coarse & Medium & Fine & Coarse & Medium & Fine \\
\hline Intake & 15,309 & 26,390 & 50,912 & 13,520 & 23,800 & 46,872 \\
\hline Rotor & 168,831 & 345,870 & 646,978 & 155,740 & 324,598 & 611,856 \\
\hline Diffuser-1 & 178,389 & 372,890 & 777,956 & 164,554 & 349,792 & 738,486 \\
\hline Diffuser-2 & 159,327 & 344,260 & 651,407 & 147,316 & 323,544 & 617,820 \\
\hline All domains & 521,856 & $1,089,410$ & $2,127,253$ & 481,130 & $1,021,734$ & $2,015,034$ \\
\hline
\end{tabular}




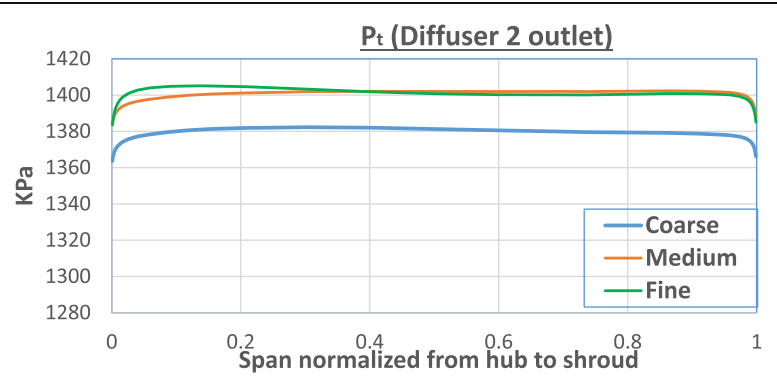

Fig. 4 Outlet total pressure for different grid refinement

of interest into small sub-regions, called control volumes. The working fluid is air, with a molar mass equal of $28.96 \mathrm{~kg} / \mathrm{kmol}$. The thermodynamic properties have been obtained with the ideal gas equation of state, and with a four-coefficient zero-pressure polynomial equation for the specific heat capacity.

For the root mean square residuals of all equations, the convergence of the steadystate simulations was set to $1 \times 10^{-5}$ and was controlled by a physical timescale equal to $(1 / \omega)$, where $\omega$ is the angular velocity given in $\mathrm{rad} / \mathrm{s}$.

All the blades and end walls are considered as smooth walls. The values of the boundary conditions and other input parameters are listed in Table 3. Ideal gas air is used as a working fluid. A single blade passage per row is considered by applying periodic boundary conditions and a mixing plane approach at the rotating impeller and the stationary vanned diffuser. This approach performs a circumferential averaging of the fluxes through bands on the interface, and steady-state solutions are then obtained in each reference frame. Therefore, the transient interaction effects are not accounted for.

\section{Validation of the model}

To examine the accuracy of the numerical model, the whole flow through the compressor is simulated for different rotational speeds. The model is validated by comparing the compressor pressure ratio and outlet total temperature from numerical results with experimental data at different speeds and corrected mass flow rates $\left(\dot{m}_{\text {corr }}\right)[19]$, as seen in Figs. 5 and 6.

Table $\mathbf{3}$ Inlet and outlet boundary conditions

\begin{tabular}{ll}
\hline Inlet boundary conditions & \\
\hline Speed of rotation (impeller) & $43,500 \mathrm{rpm}$ \\
Flow regime & Subsonic \\
Turbulence & Medium (intensity = 5\%) \\
Total pressure & $710 \mathrm{kPa}$ \\
Total temperature & $560 \mathrm{~K}$ \\
Exit boundary condition & \\
Mass flow rate & $5.4 \mathrm{~kg} / \mathrm{s}$ \\
\hline
\end{tabular}




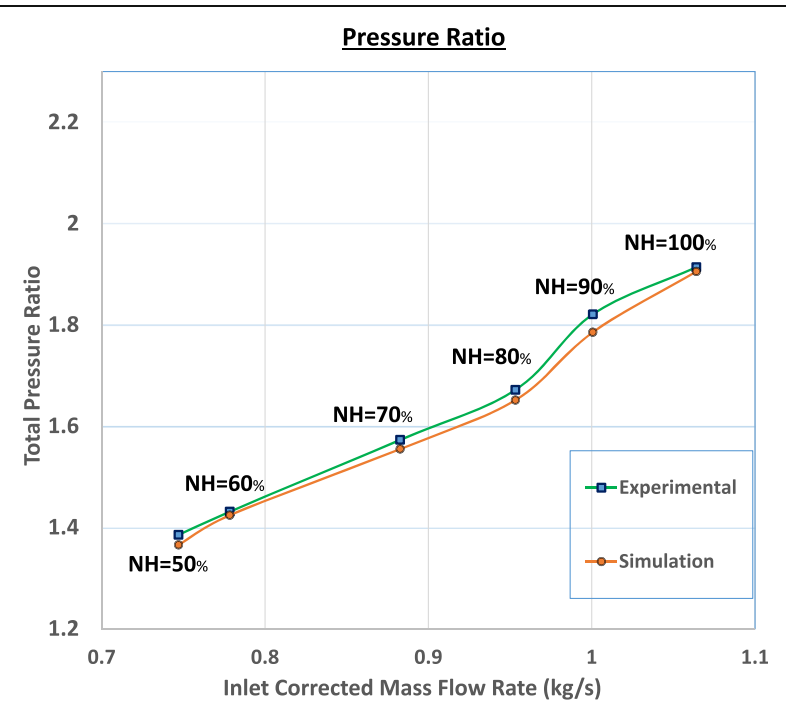

Fig. 5 Pressure ratio validation

$$
\dot{m}_{\text {corr }}=\frac{\sqrt{T_{\text {o in }} / T_{\text {ref }}}}{P_{\text {o in }} / P_{\text {ref }}}
$$

where

$p_{o}$ in and $T_{o}$ in are the total pressure and temperature at the compressor inlet, respectively.

$p_{\text {ref }}$ and $T_{\text {ref }}$ are the reference pressure and temperature, respectively.

According to the above diagrams, $2 \%$ maximum disagreement in pressure ratio at speed ratio $\mathrm{NH}=90 \%$ and $4 \%$ maximum disagreement in outlet total temperature at $\mathrm{NH}=80 \%$ are observable respectively between experimental and simulation results at the maximum efficiency point. Discrepancies between numerical and experimental results can be attributed to the degree of conforming between the numerical simulation and the experimental data, the accuracy of measurements, and the method of measurements as the experimental measurements give the pressure and temperature distribution along the shroud while the calculations give simple basic mass-averages of the CFD results.

\section{Results and discussion}

The blockage of the flow from the impeller to the first set of vaned diffusers is one of the most important aspects to account for in the vaned diffuser. Reducing the total pressure losses and consequently improving the diffuser efficiency can be accomplished by overcoming this blockage [20]. In the present work, as mentioned before, flow through the compressor stage with splitter vaned diffuser is investigated to get the effect of the circumferential location of the splitter vanes on diffuser performance. The reference case is the diffuser with thirty splitter vanes that have the same main blades' angle distribution along the chord direction and the same thickness distribution along the relative chord length, Table 1 . The trailing edge of the splitter vanes is located at the same radius as that of the main vane, and its circumferential position is at the middle of the passage surrounded by two adjacent main vanes (Fig. 7). 


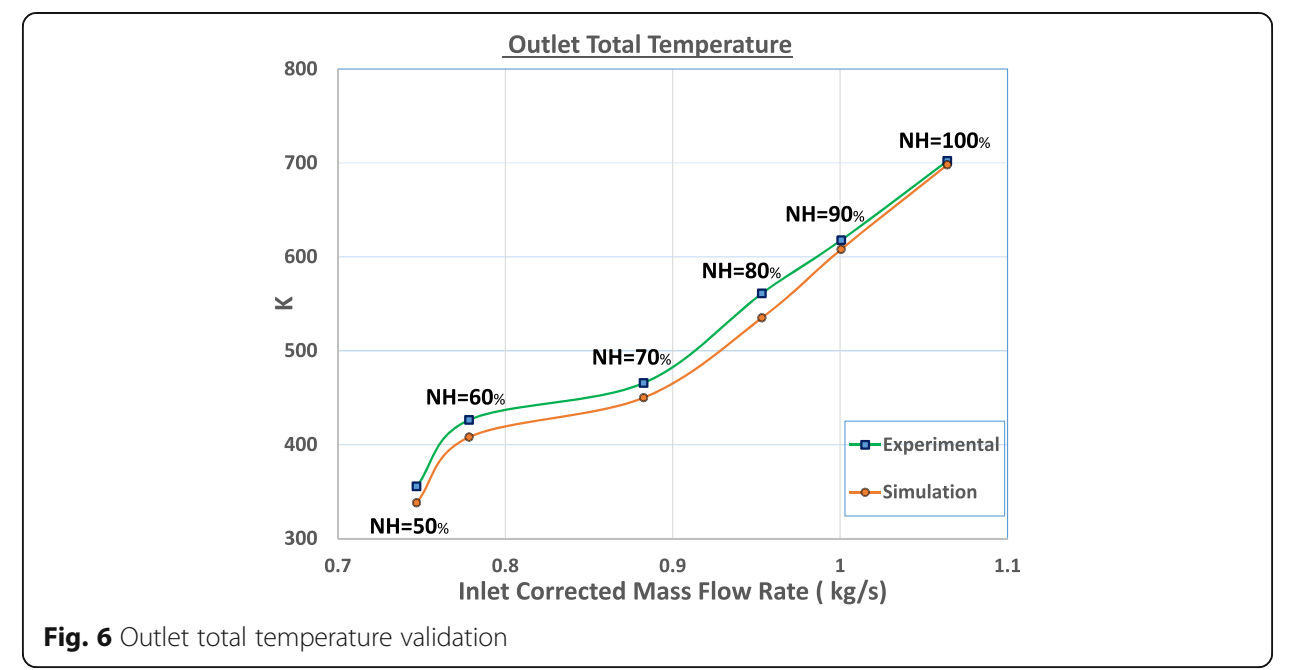

Six different cases were studied and compared for the nominal operating conditions of the compressor. The splitter vanes are shifted (by one degree for each case) in the circumferential direction, three cases (A1, A2, A3) toward the pressure side of the adjacent main blades and three cases (A4, A5, A6) toward the suction side as shown in Fig. 8 . A0 designates the reference case where the location of the splitter is mid-distance between two main blades.

The overall performance of the diffusers is measured by the total pressure loss and the static pressure recovery coefficients. The pressure recovery coefficient, which describes the gain in static pressure as a result of transforming the inlet dynamic pressure, is defined as the ratio of static pressure rise to diffuser inlet dynamic pressure, as follows:

$$
C_{p r}=\frac{p_{\text {out }}-p_{\text {in }}}{p_{\text {tin }}-p_{\text {in }}}
$$

while the total pressure loss coefficient is defined as:

$$
K_{\mathrm{pl}}=\frac{p_{\text {tin }}-p_{\text {tout }}}{p_{\text {tin }}-p_{\text {in }}}
$$

where $p_{\mathrm{t}}$ in and $p_{\text {in }}$ are the total and static pressure at the inlet of the diffuser, respectively.

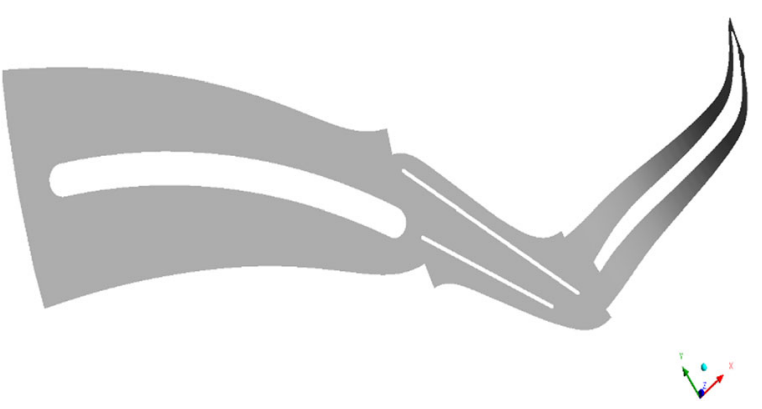

Fig. 7 Blade to blade view of the impeller and diffusers 


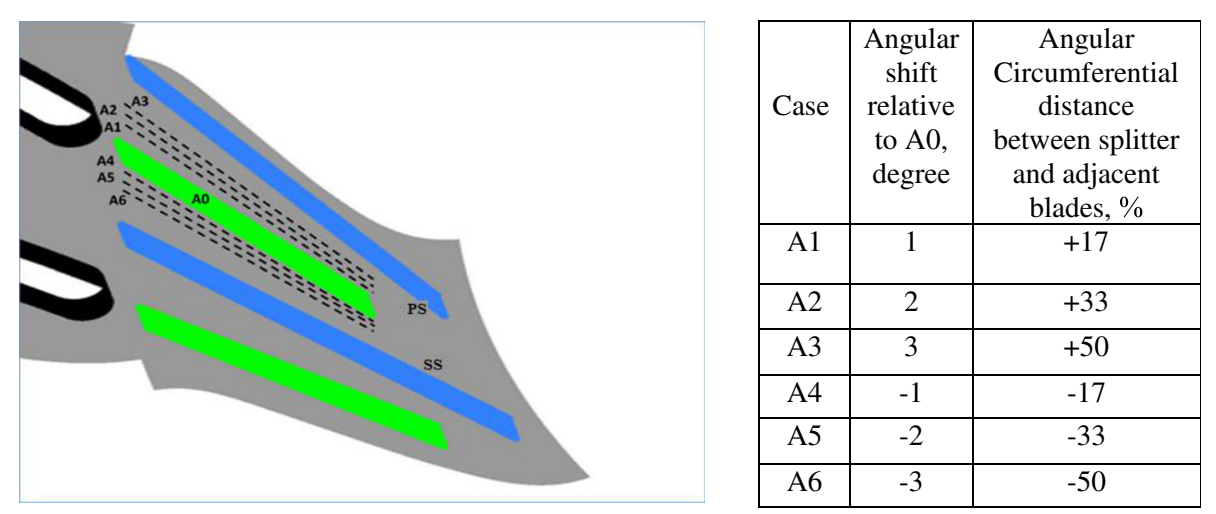

Fig. 8 Geometric configuration for splitter vanes and relative locations of investigated cases

$p_{\mathrm{t}}$ out and $p_{\text {out }}$ are the total and static pressure at the outlet of the diffuser, respectively.

The pressure recovery coefficient and the total pressure loss coefficient will depend to a great extent on the averaging procedure to determine the static and total pressures. Mass averaging is used to calculate total pressures, while area averaging is used to calculate static pressures in the CFX post-processing, such as:

$$
\begin{aligned}
& \text { Area average }=\frac{\int \phi d A}{A} \\
& \text { Mass average }=\frac{\int \phi d \dot{m}}{\dot{m}}
\end{aligned}
$$

where $\varnothing$ is an arbitrary scalar property of the flow.

Figures 9 and 10 show total pressure loss and static pressure recovery coefficients with respect to different configurations of splitter vanes used in the present analysis at the exit of diffuser- 1 and diffuser-2, respectively.

It is clearly observed that the configuration corresponding to (A2) represents the best performance generally as the static pressure recovery coefficient through the diffusers is better by $17 \%$ compared to the original configuration. Other configurations show reasonable improvement of the performance for stage static pressure recovery when compared to configuration (A0) by about (4:8)\%.

However, at the exit of diffuser-1, configurations A4, A5, and A6 annihilate the static pressure recovery by about $2: 7 \%$ compared with the original configuration (A0), but $C_{\mathrm{pr}}$ returns to increase at the end of the whole stage by about $4: 13 \%$.

The physical reasoning for the above-observed phenomena could be deduced by carefully analyzing the total pressure and the velocity contours at $50 \%$ span of diffusers 1 and 2, as shown in Figs. 11, 12, and 13, and the entropy contours at different chord length of diffusers 1 and 2, as shown in Figs. 14, 15, 16, and 17, obtained for the configurations which are mentioned above. For a detailed discussion, configurations A2 and A will be selected to represent the best and the worst performance, respectively, compared to the original configuration (A0).

It is well known that the area ratio of the diffuser is one of the parameters that needs to be considered during the design of a diffuser [21]. The ratio of the cross-sectional area of the diffuser outlet to that of the diffuser throat plays a significant role in pressure recovery. 


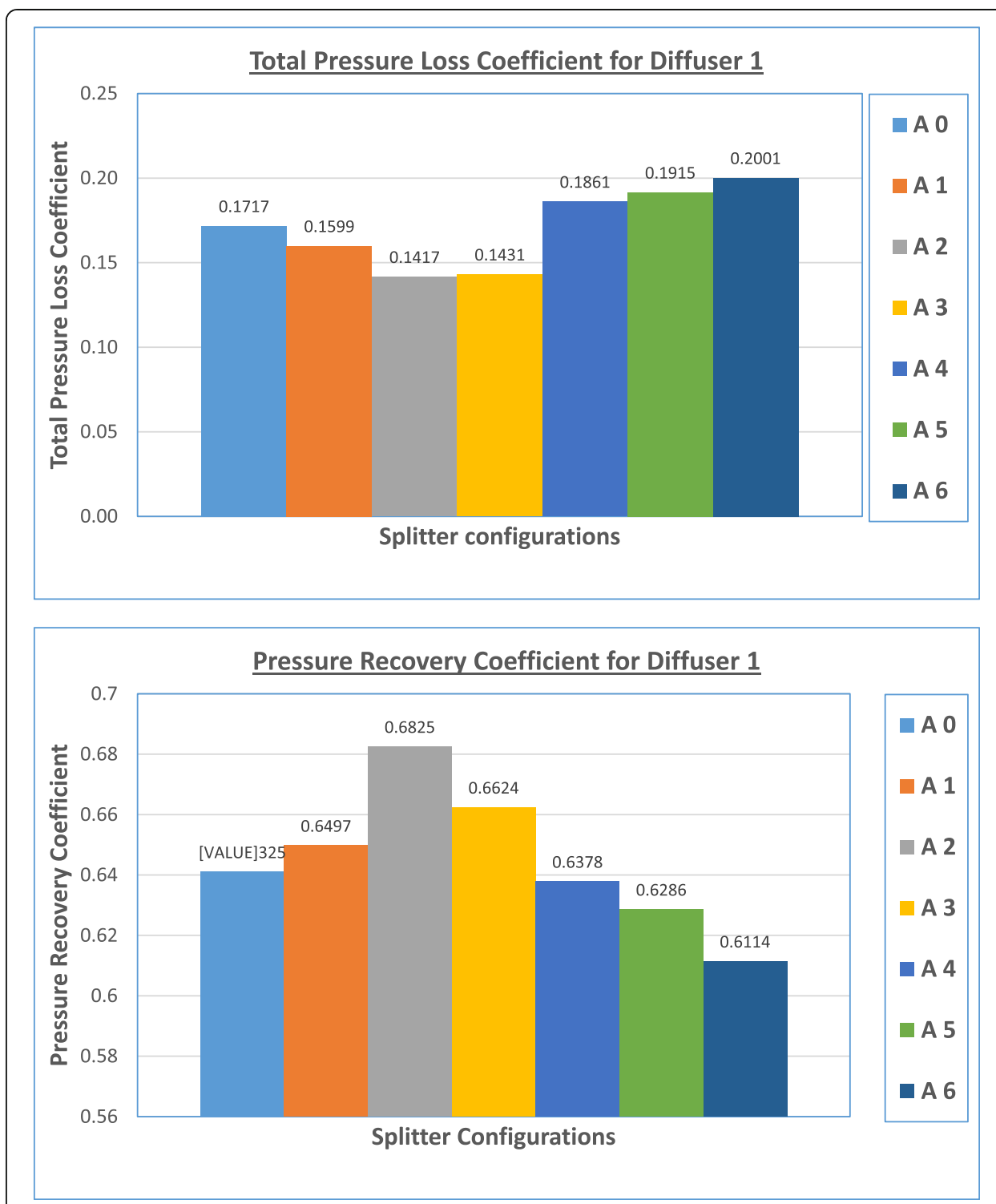

Fig. 9 Total pressure loss coefficient and static pressure recovery coefficient at diffuser-1 exit for various configurations

According to CFX calculations, the pressure recovery factor for diffuser-1 is 0.641 , while the design area ratio predicts a $C_{\mathrm{pr}}$ value of 0.721 . The basic reason for this discrepancy is flow separation. This occurs when the boundary layers on the walls break away and cause an unfavorable reduction in performance. This break-away is also referred to as a stall that creates backflow in the diffusing region.

The performed CFD calculations have shown that the presence of a splitter in diffuser-1 in the original configuration does not provide the best compressor performance. Owing to narrowing down the flow passage, the wetted area increases, and the flow accelerates in the diffuser passage, which induces an adverse pressure gradient and increases the surface friction loss. That is seen clearly in Fig. 11, at 50\% span for the original position of the splitter, high-pressure difference $(100: 170 \mathrm{kPa})$ between the pressure side of the main blade and the suction side of the splitter along the domain of 


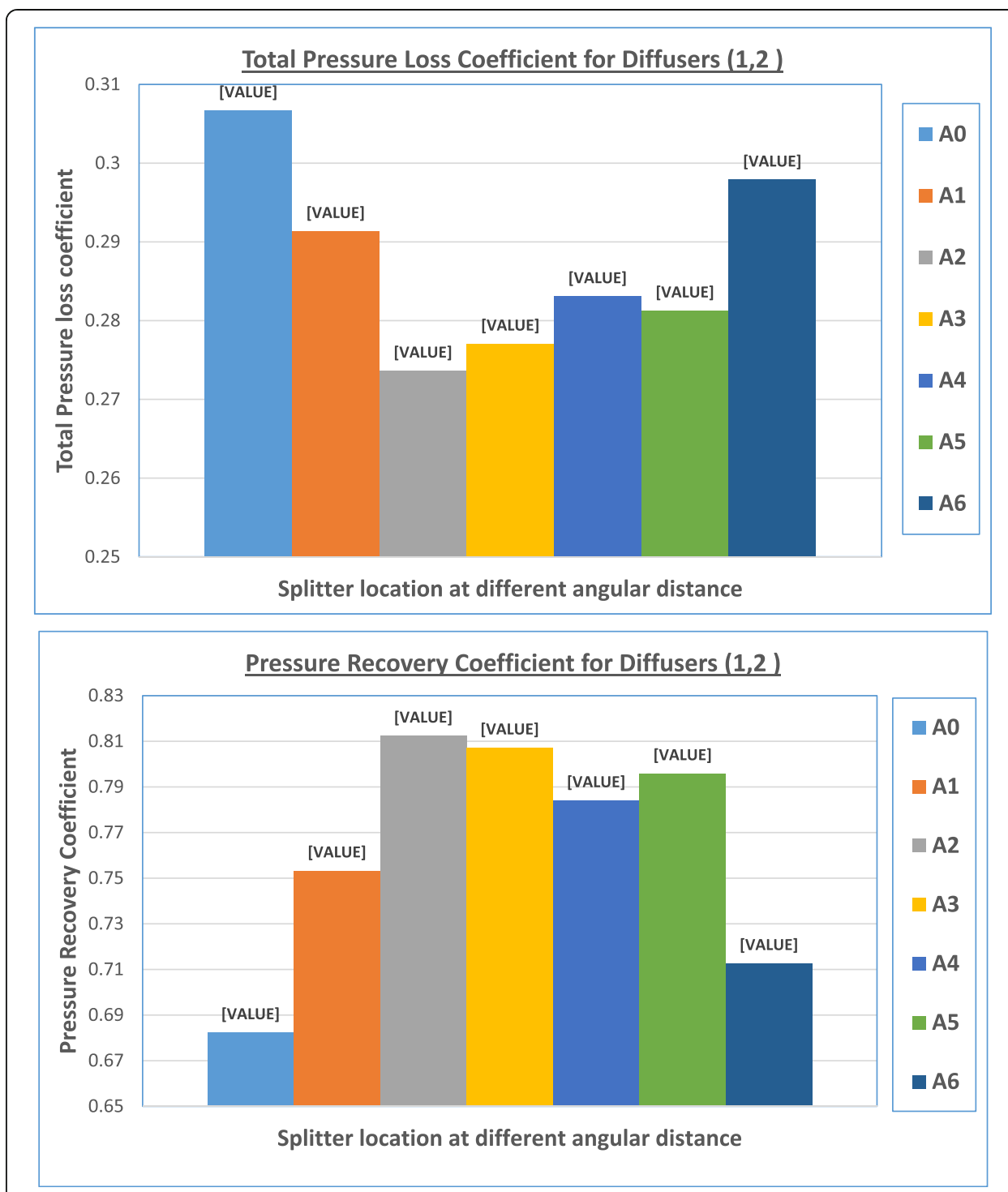

Fig. 10 Total pressure loss coefficient and static pressure recovery coefficient for diffusers 1 and 2

diffuser-1, leads to the occurrence of flow separation at: (1) the pressure side of the main blade from $30 \%$ chord length till its trailing edge and (2) the pressure side of the splitter at its leading edge extends to $50 \%$ chord length.

Comparing Figs. 11 and 12 reveals that by reducing the circumferential width of the flow path passage as in configuration (A2), however increasing the friction loss on the blades surfaces than the original diffuser (A0), but the pressure difference is reduced between the blades' surfaces, the speed difference is also reduced, increase the flow velocity in the radial direction. As a result, the flow becomes more homogenous and the extension of the separation region occurring at the pressure side of the main blade disappeared completely except that separation attached to the pressure side of the splitter blade is reduced and shifted downstream.

Increasing the outlet radial velocity from diffuser- 1 leads to rapid pressure drop in the upstream portion of diffuser- 2 blade. This pressure drop is attached by severe increase in pressure gradient in the downstream portion of diffuser- 2 blade 


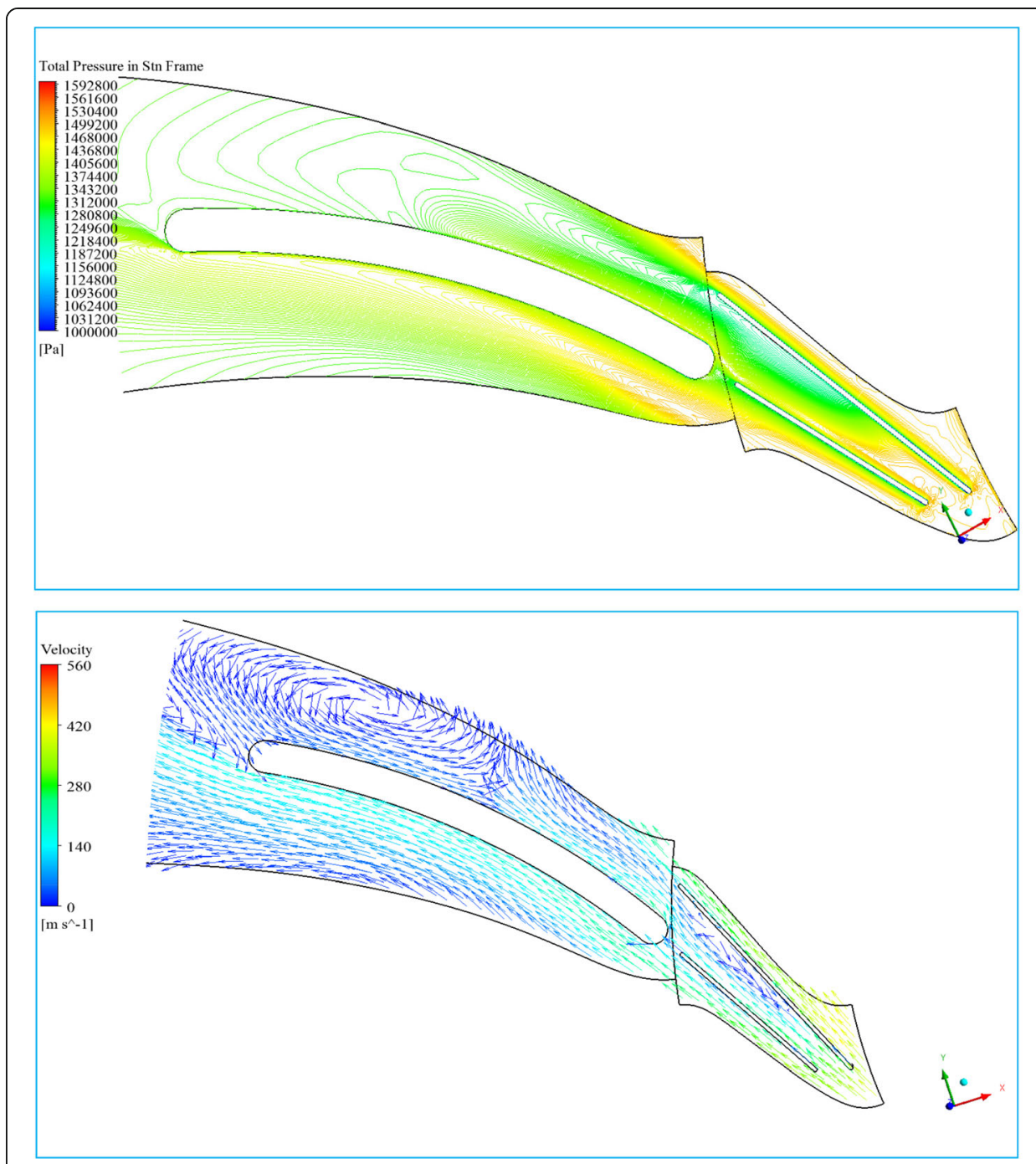

Fig. 11 Total pressure contours and velocity vectors at 50\% span for configuration (A0)

overcomes the boundary layer and the viscous shear on the suction side of the blade, which leads to forming vortices in the rear part of diffuser-2, as shown by velocity vectors in Fig. 12 . What happens in diffuser-2 does not badly affect the overall $C_{\mathrm{pr}}$ at diffuser-2 exit, which still represents the highest $C_{\mathrm{pr}}$ for all configurations.

Resultant of these observations, the static pressure of the modified diffuser (A2) is raised by means of increase in static pressure recovery coefficient $\left(C_{\mathrm{pr}}\right)$ by about $17 \%$ than configuration (A0). Also, the pressure ratio is raised by about $2 \%$, and the efficiency of the whole stage is raised by about $2.01 \%$ compared to the original design (A0). Further moving the splitter toward the pressure side of the diffuser-1 main blade, configuration (A3), the pressure recovery coefficient $\left(C_{\mathrm{pr}}\right)$, on the contrary, decreases by about (2\%) than configuration (A2), but still higher than (A0) by about (15\%).

On the other side, situating the splitter at different angular distances between the splitter and the main blade's suction side of the neighbor domain, as in configurations (A4, A5, and A6), a great pressure gradient reaches $200 \mathrm{kPa}$ is induced between the 


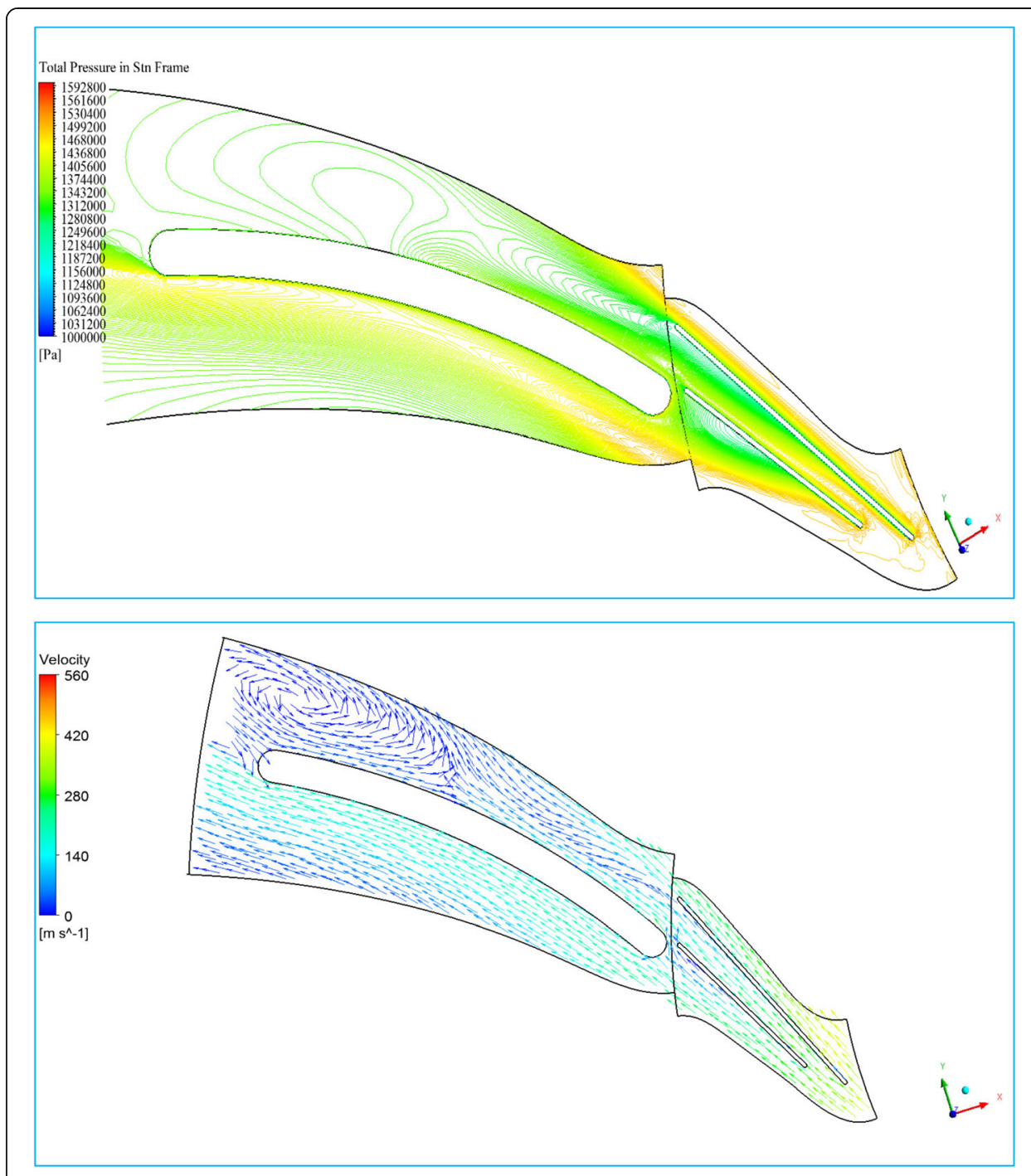

Fig. 12 Total pressure contours and velocity vectors at 50\% span for configuration (A2)

pressure side of the main blade and the suction side of the splitter along the flow passage of diffuser-1, as shown in Fig. 13, the distortion of through-flow pattern and the formation of secondary flow are attributed to the presence of swirling flow inside the diffuser-1. High-intensity vortices as well as flow instability leading to the detachment of the boundary layer on the pressure side of the blades. Separation was observed at the pressure-side of the main blade near $25 \%$ chord position and grew toward downstream, then the separated fluid moved to the middle of the passage at $50 \%$ chord position and occupied half of the passage cross-section, as shown by velocity vectors in Fig. 13.

All that leads to annihilating the static pressure recovery coefficient $\left(C_{\mathrm{pr}}\right)$ by about $7 \%$ compared with the original configuration (A0) at the exit of diffuser- 1 . Once the circumferential width of the flow path passage is increased, the speed difference caused is also increased, which reduces the flow velocity in the radial direction. Then, a marginally pressure drop in the upstream portion of diffuser-2 blade is noticed followed by a gradual increase in pressure gradient in the downstream portion due to back pressure 


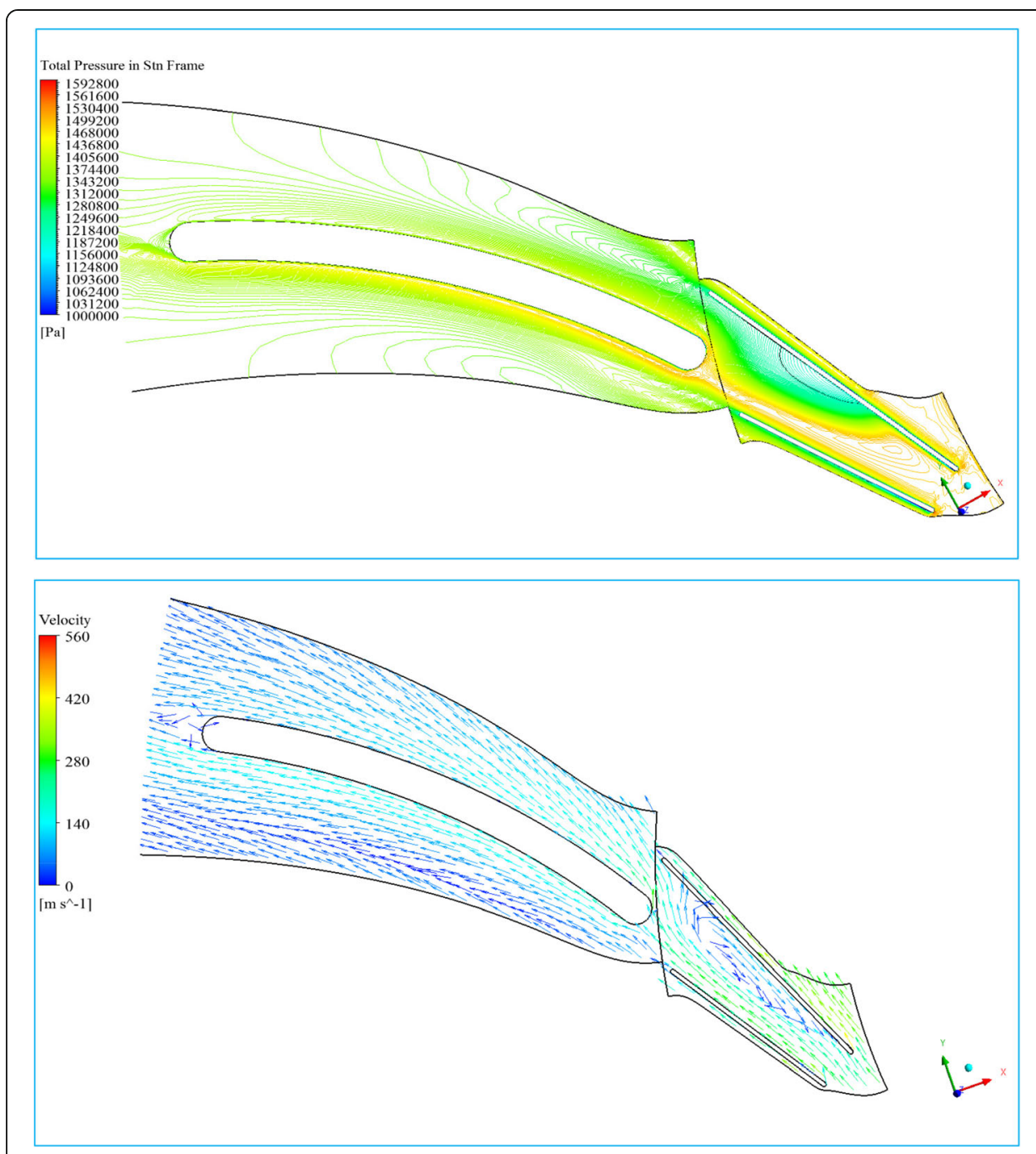

Fig. 13 Total pressure contours and velocity vectors at 50\% span for configuration (A6)

from the volute. This small difference in the pressure overcomes the formation of vortices and leads to improve the flow in diffuser-2. As a result, the static pressure recovery coefficient $\left(C_{\mathrm{pr}}\right)$ for the whole stage is increased by about $4: 13 \%$, as shown in Fig. 10, and the stage efficiency and pressure ratio are increased by about $0.17 \%$ and $0.2 \%$, respectively, compared to configuration (A0).

The above observations are supported by analyzing contours of static entropy along the stream wise of diffusers 1 and 2, as shown in Figs. 14, 15, 16, and 17. At 30\% chord length of diffuser-1, it is observed that elevated entropy areas are accumulated close to solid surfaces, i.e., blades and shroud surfaces, especially the shroud of the main blade. Continuing toward $60 \%$ chord length, it is noticed that the elevated entropy area is accumulated close to the whole span of the pressure side of the splitter likewise the pressure side of the main blade and it displays a quick diffusion toward the center of flow path, i.e., between the pressure side of the main blade and suction side of the splitter. Consequently, moving toward the trailing edge of diffuser-1 blades, at $90 \%$ chord, the entropy close to the shroud of diffuser-1 is reduced and the accumulated elevated 


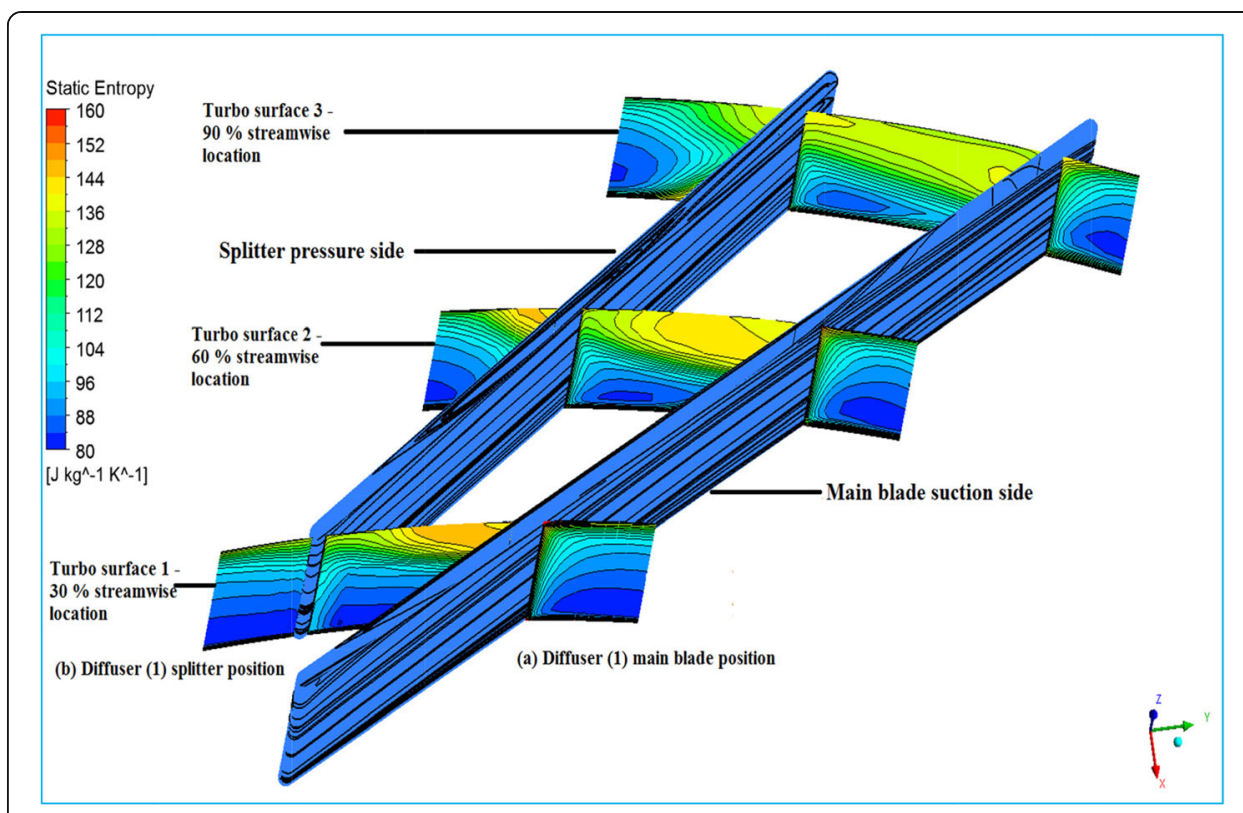

Fig. 14 Entropy distribution at 30,60, and 90\% chord of diffuser-1

entropy on the pressure side of the splitter propagates toward the neighbor flow channel, i.e., between the pressure side of splitter and suction side of the neighbor main blade, as shown in Fig. 15. Further moving toward, 25\% chord length of diffuser-2 blade, the elevated entropy contours area is extended along the shroud of the diffuser. At $50 \%$ chord length of diffuser-2 blade, the elevated entropy contours diffuse toward the mid-span on the suction surface of the blade. At the trailing edge of diffuser-2 blade, the entropy intensity at the suction surface is reduced.

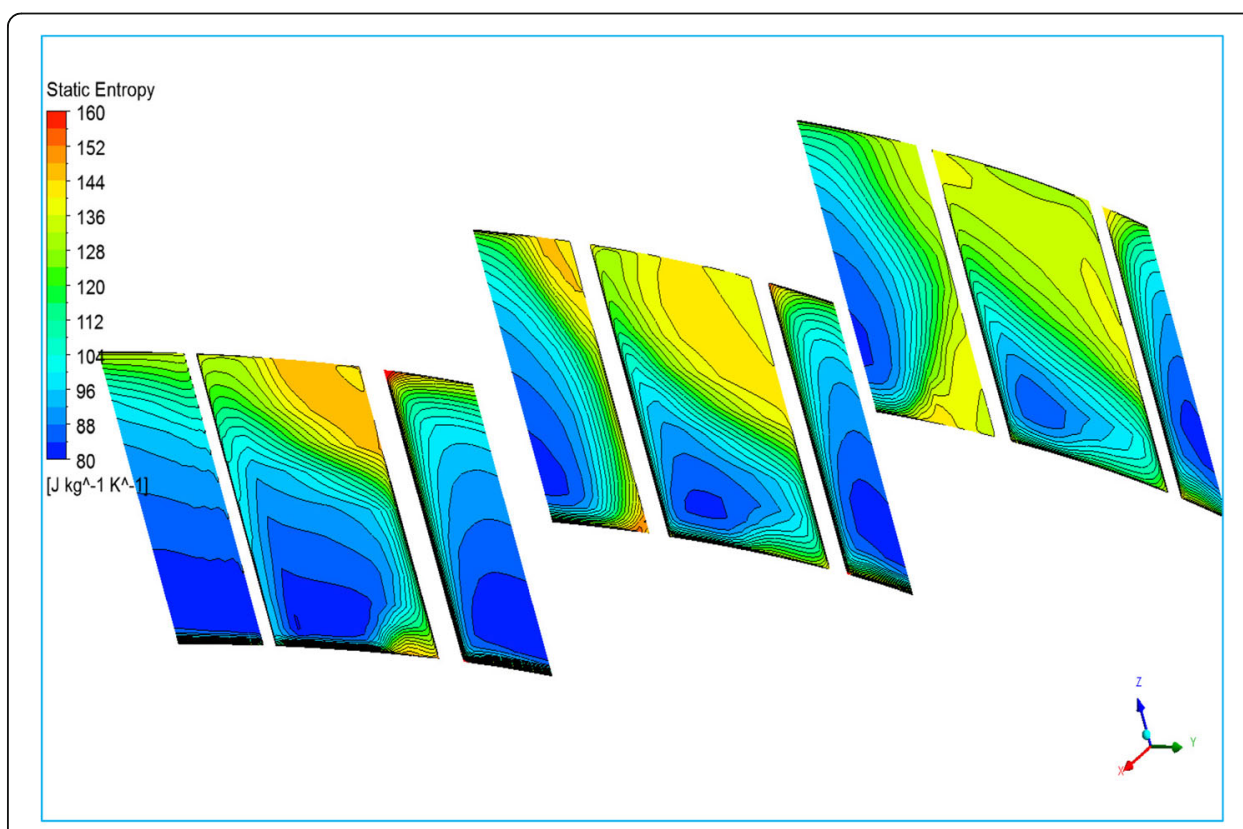

Fig. 15 Entropy distribution at 30,60, and 90\% chord of diffuser-1 for original configuration 


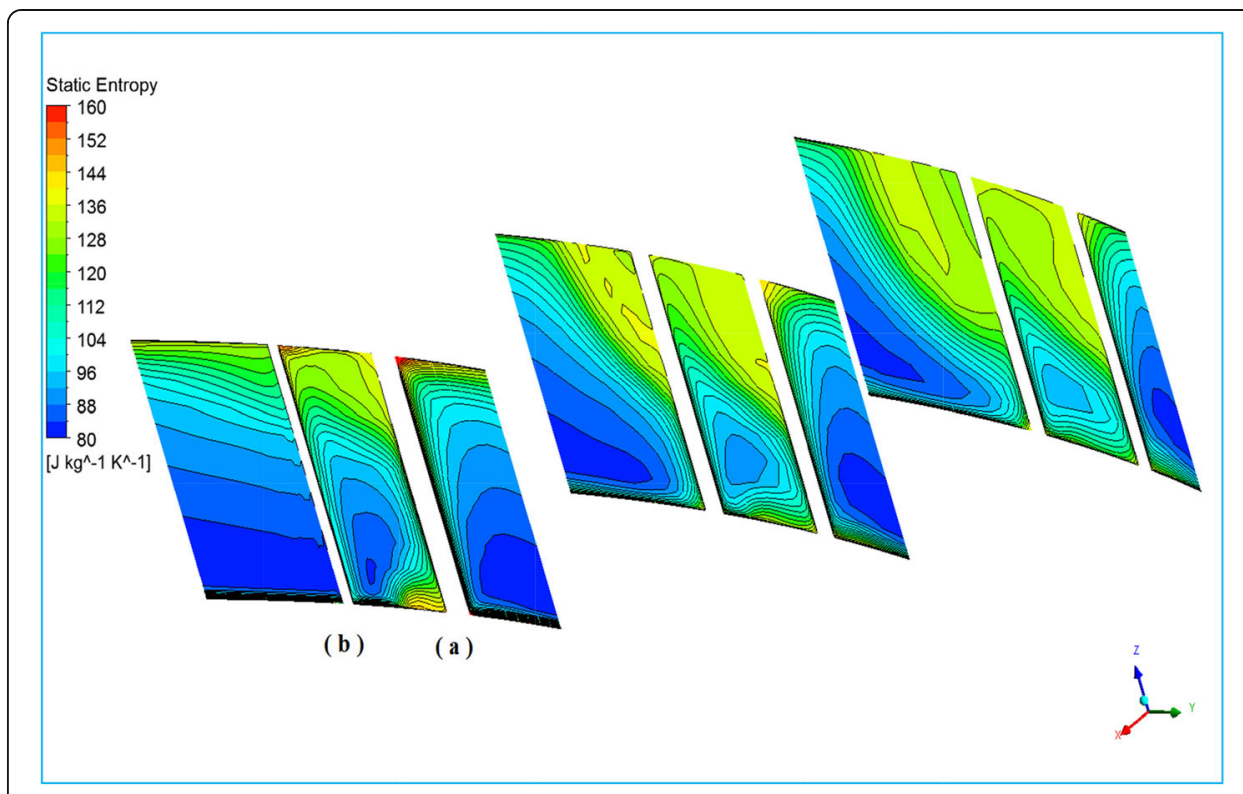

Fig. 16 Entropy distribution at 30,60, and 90\% chord of diffuser-1 for configuration A2

For configuration A2, the effect of modifying splitter position on suppressing the flow separation is illustrated in Fig. 16, where the static entropy contours superimposed with isolines at different cross flow planes of the diffusers are presented. The region of elevated entropy areas is decreased compared to the preliminary design along the pitch of diffusers 1 and 2. A significant performance improvement is observed in the modified diffuser and the whole compressor stage. Not only the elevated entropy area is reduced, but also more uniform fluid flow is also observed along the diffuser-1 domain. The modification of splitter blades makes that the friction loss in the original impeller is

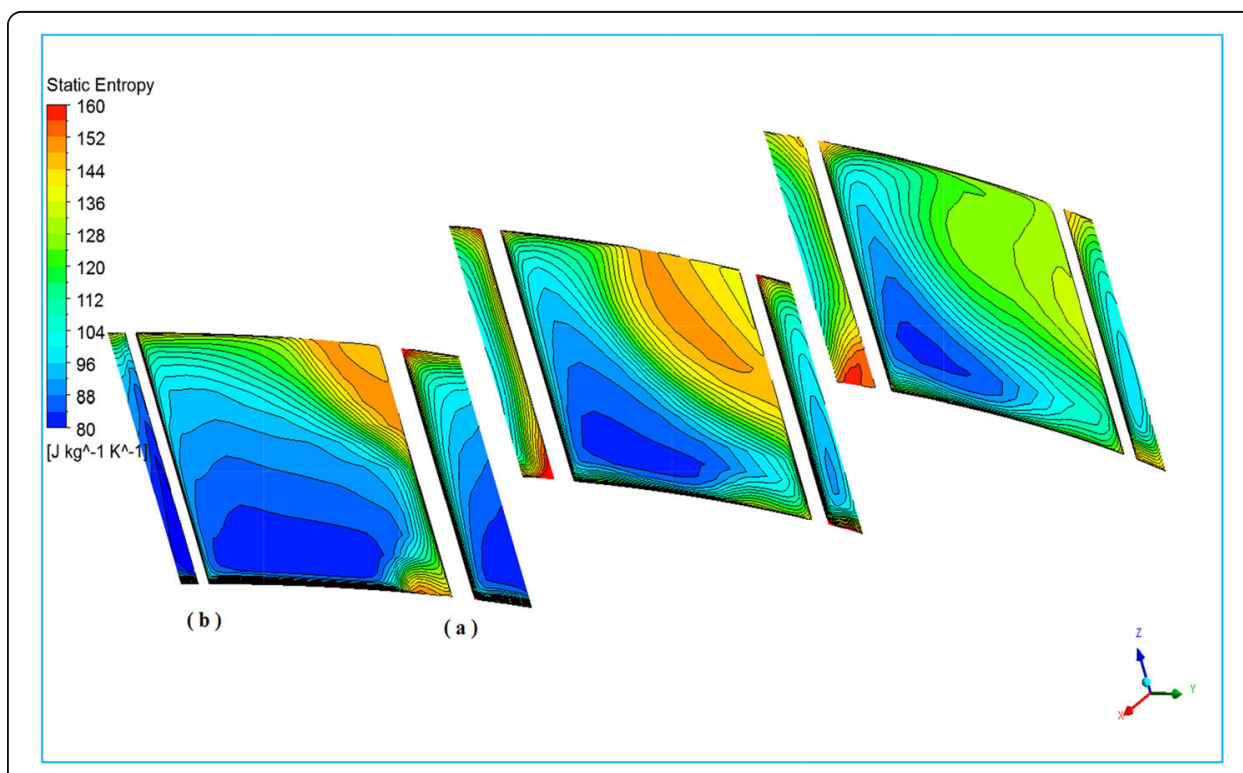

Fig. 17 Entropy distribution at 30, 60, and 90\% chord of diffuser-1 for configuration A6 
reduced, as the velocity and the Mach number on blade surfaces are lower in the modified impeller.

On the contrary, locating the splitter, far away from the pressure side of the main blade in the same domain, and close to the suction side of the main blade in the neighbor domain, configurations A4, A5, and A6, it is noticed that at 30\% chord of diffuser1 , the elevated entropy area becomes more intensive and accumulated close to the solid surface of the main blade, i.e., blade, shroud, and hub surfaces. Continuing toward the $60 \%$ chord, it is observed that a high elevated entropy area close to the pressure side of the main blade displays a quick diffusion toward the center of conduits, and a new high entropy area is accumulated at the pressure side of the splitter. The entropy loss is directly proportional to the surface pressure distribution and the dissipation coefficient, thus more severe entropy loss seems to happen at the main blade pressure side due to relatively higher surface pressure distribution and much larger extent of turbulent boundary layer. Consequently, moving toward the trailing edge at $90 \%$ chord, the elevated entropy close to the pressure side of the main blade is reduced while increased at the hub section corner for the splitter pressure side, as shown in Fig. 17.

Resultant to all the above observations, the stage performance in the form of stage efficiency and pressure ratio, according to the splitter position in diffuser-1, can be remarked as shown in Table 4.

\section{Conclusions}

In general, providing splitter vanes in the diffuser, at judiciously chosen locations, tends to improve the performance of the centrifugal compressor in terms of higher static pressure recovery coefficients and reduced total pressure loss coefficients. But there is the best position of the splitter blade in the diffuser's circumferential position. This position is not in necessity at the middle of the circumferential distance between the diffuser's main blades. From the present work, it was found that:

1) The overall centrifugal compressor performance illustrates a significant improvement after positioning the splitter at $33 \%$ of the angular distance closer to the main blade's pressure side. It is observed that the static pressure recovery coefficient at the exit of the whole compressor stage is increased by $17 \%$, the pressure ratio is increased by $1.13 \%$, and the stage efficiency is increased by $2.01 \%$ (absolute) compared to the original configuration.

2) Further moving the splitter closer toward the pressure side of the diffuser-1 main blade than (33\%) of the angular distance, the pressure recovery coefficient, on the contrary, decreases by about (2\%) than this configuration, but still higher than original splitter position by about (15\%).

Table 4 Centrifugal compressor performance according to splitter location

\begin{tabular}{|c|c|c|c|c|c|c|c|}
\hline $\begin{array}{l}\text { Splitter } \\
\text { location } \\
\text { Performance }\end{array}$ & $\begin{array}{l}\text { (17\%) } \\
\text { Toward } \\
\text { pressure } \\
\text { side }\end{array}$ & $\begin{array}{l}(33 \%) \\
\text { Toward } \\
\text { pressure } \\
\text { side }\end{array}$ & $\begin{array}{l}(50 \%) \\
\text { Toward } \\
\text { pressure } \\
\text { side }\end{array}$ & $\begin{array}{l}\text { Original } \\
\text { location }\end{array}$ & $\begin{array}{l}\text { (17\%) } \\
\text { Toward } \\
\text { suction } \\
\text { side }\end{array}$ & $\begin{array}{l}\text { (33\%) } \\
\text { Toward } \\
\text { suction } \\
\text { side }\end{array}$ & $\begin{array}{l}\text { (50\%) } \\
\text { Toward } \\
\text { suction } \\
\text { side }\end{array}$ \\
\hline Efficiency & $\begin{array}{l}80.08 \%(+ \\
0.71 \%)\end{array}$ & $\begin{array}{l}81.38 \%(+ \\
2.01 \%)\end{array}$ & $\begin{array}{l}81.03 \%(+ \\
1.66 \%)\end{array}$ & $79.37 \%$ & $\begin{array}{l}80.17 \%(+ \\
0.8 \%)\end{array}$ & $\begin{array}{l}80.23 \%(+ \\
0.86 \%)\end{array}$ & $\begin{array}{l}79.54 \%(+ \\
0.17 \%)\end{array}$ \\
\hline Pressure ratio & 1.931 & 1.95 & 1.945 & 1.911 & 1.933 & 1.934 & 1.924 \\
\hline
\end{tabular}


3) Locating the splitter at different angular distances far away from the pressure side of the main blade, i.e., closer to the suction side of the main blade in the neighbor domain, leads to annihilate the static pressure recovery coefficient of the diffuser by about $4: 7 \%$ compared with the original splitter position.

Finally, moving the splitter in the vaned diffuser to $33 \%$ of the angular distance achieves the best compressor performance, where the diminished loss from the suppressed flow separation is more prevailing, the instigated friction losses from splitter surfaces is less critical, and the compressor is able to operate at wider range due to decreasing choke's margin.

\section{Abbreviations}

A0: original configuration; A $(1,2, \ldots)$ : Modified configurations; CFD: Computational fluid dynamics; $C_{p r}$ : Static pressure recovery coefficient; GIL: Grid independence limit; $K_{\mathrm{p}}$ : Total pressure loss coefficient; $\mathrm{NH}$ : High-pressure compressor speed; $p$ : Static pressure; $p_{\text {ref }}$ : Reference pressure $=101.325 \mathrm{kPa} ; p_{\mathrm{t}}$ : Total pressure; $p_{\mathrm{o}}$ in: Total pressure at the compressor inlet; PS: Blade pressure side; RANS: Reynold-average Navier-Stokes equations; SS: Blade suction side; SST: Shear stress transport; S1: Diffuser-1; S2: Diffuser-2; $T_{0}$ in: Total temperature at the compressor inlet; $T_{\text {ref: }}$ Reference temperature $=288.15 \mathrm{~K} ; \mathrm{VD}$ : Vaned diffuser; $\omega$ : Angular velocity; $\varnothing$ : Arbitrary scalar property of the flow

\section{Acknowledgements}

Not applicable.

\section{Authors' contributions}

MGK revised the analyzed results and performed the final modifications and revision of the manuscript to be in the final form. HSS revised the paper and made the primary modifications to the manuscript. SMA performed the simulation and analyzed the results. HMA acquired the data, prepared the primary fittings for the simulation, collected the results, and wrote the paper. All authors read and approved the final manuscript.

\section{Funding}

The authors declare that they receive no funding.

\section{Availability of data and materials}

The datasets used and analyzed during the current study are available from the corresponding author on reasonable request.

\section{Declarations}

\section{Competing interests}

The authors declare that they have no competing interests.

Received: 13 July 2021 Accepted: 26 October 2021

Published online: 11 December 2021

\section{References}

1. Dean R, Senoo Y (1960) Rotating wakes in vaneless diffuser. Journal of Basic Engineering 82(3):254-263. https://doi.org/1 $0.1115 / 1.3662659$

2. Eckardt D (1975) Instantaneuos measurements in the jet-wake discharge flow of a centrifugal compressor impeller. Journal of Engineering for Power 97(3):337-346. https://doi.org/10.1115/1.3445999

3. Krain H (1981) A study on centrifugal impeller and diffuser flow. Journal of Engineering for Power 103(4):688-697. https://doi.org/10.1115/1.3230791

4. Hillewaert K, Van den Braembussche R. A (1999) "Numerical simulation of impeller-volute interaction in centrifugal compressors", Journal of Turbomachinery, 121:603-608, 3, DOl: https://doi.org/10.1115/1.2841358.

5. Millour V (1988) "3D flow computations in a centrifugal compressor with splitter blade including viscous effect simulation", $16^{\text {th }}$ Congress. International Council for Aeronautical Societies 1:842-847

6. Drtina P, Dalbert P, Schachenmann A (1993) "Optimization of a diffuser with splitter by numerical simulation", ASME paper, 93-GT-110.

7. Yagnesh Sharma N, Vasudeva Karanth K (2009) "Numerical analysis of a centrifugal fan for improved performance using splitter vanes", Int. J. Mech., Aero., Ind., Mecha., Manuf. Eng., 3(12), pp. 1520-1526.

8. Fradin C (1987) "Investigation of the three-dimensional flow near the exit of two backswept transonic centrifugal impellers," Proc. of the Eighth International Symposium in Air Breathing Engines, pp. 149 -155.

9. Gui L, Gu C, Chang H (1989) "Influences of splitter blades on the centrifugal fan performances", ASME paper, 89-GT-33.

10. Clements W, Artt D (1989) "The influence of diffuser vane leading edge geometry on the performance of a centrifugal compressor", ASME Paper, No. 89- GT-163.

11. Gottfried D, Fleeter S (2002) "Impeller blade unsteady aerodynamic response to vaned diffuser potential fields", AIAA J. Propulsion Power 18(2):472-480. https://doi.org/10.2514/2.5958 
12. Teipel I, Wiedermann A (1987) "Computation of flow fields in centrifugal compressor diffusers with splitter vanes", The International Gas Turbine Congress, (2) pp: II 311- 317.

13. Oana M, Kawamoto O, Ohtani H, Yamamoto Y (2002) "Approach to high performance transonic centrifugal compressor," AIAA paper 3536.

14. Nassar A, Nagpurwala QH, Bramahanada K (2006) Design and CFD investigation of centrifugal compressor for turbocharger and parametric study on splitter blades. SAS Technology, Volume V NO. 2

15. Malik A, Zheng Q, Zaidi A, Fawzy H (2018) Performance enhancement of centrifugal compressor with addition of splitter blade close to pressure surface. Journal of Applied Fluid Mechanics 11(4):919-928. https://doi.org/10.29252/jafm.11.04.2 8658

16. Madhwesh N, Vasudeva Karanth K, Yagnesh Sharma N (2011) "Impeller treatment for a centrifugal fan using splitter vanes - a CFD approach", Proceedings of the World Congress on Engineering, Vol. III, WCE 2011, July 6 - 8, London, U.K.

17. Xiao HE, Xinqian ZHENG, Jie WEI, Hanxuan ZENG (2016) "Investigation of vaned diffuser splitters on the performance and flow control of high-pressure ratio centrifugal compressors", Turbomachinery Technical Conference and Exposition GT2016. Seoul, South Korea

18. ANSYS, Inc. (2019) "ANSYS-CFX Solver Theory Guide", Release 19.0, Canonsburg, Pennsylvania, U.S.A

19. Metwally M (2007) "Investigation of fluid power system controller at start/stop conditions gas turbine engine", Ph.D thesis, Military Technical College, Cairo.

20. Cumpsty N A (1989) "Compressor aerodynamics handbook", Longmann Scientific and Technical, Essex, England, ISBN 0582-01364-X

21. Japikse D (1996) "Centrifugal compressor design and performance", Concepts ETI, Wilder, Vermont. Thomson-Shore, Inc., U.S.A

\section{Publisher's Note}

Springer Nature remains neutral with regard to jurisdictional claims in published maps and institutional affiliations.

\section{Submit your manuscript to a SpringerOpen ${ }^{\circ}$ journal and benefit from:}

- Convenient online submission

- Rigorous peer review

- Open access: articles freely available online

- High visibility within the field

- Retaining the copyright to your article 